\title{
A centralidade do trabalho em educação: retornar ao ato de ensinar na sala de aula
}

\author{
Roberto della Santa ${ }^{1}$ \\ https://orcid.org/0000-0001-7364-3267 \\ ${ }^{1}$ Universidade Nova de Lisboa, Faculdade de Ciências Sociais e Humanas, Instituto de História Contemporânea, Portugal
}

\begin{abstract}
A centralidade do trabalho em educação: retornar ao ato de ensinar na sala de aula
Resumo: $\mathrm{O}$ ato de ensinar encontra-se em situação de risco. É preciso protegê-lo, acarinhá-lo e abrir caminho. Nunca antes foi tão necessário. A isso se propõe tal ensaio. Através do método dialético, com vasta tradição no pensamento humanístico, a exposição a seguir tem como objetivo plasmar um inquérito crítico - através da revisão bibliográfica, da crítica metodológica e de apontamentos obtidos via pesquisa-ação-participante realizada em todo o território português (2017-2020) - sobre a forma e o sentido do ato de ensinar, na sala de aula, como a unidade indivisível e elemental mais básica do trabalho em educação em todos os níveis, modalidades e formatos realmente existentes.
\end{abstract}

Palavras-chave: Pedagogia Histórico-Crítica; Didática; Ato de Ensinar.

\section{The centrality of work in education: return to the teaching act in the classroom}

Abstract: The act of teaching is at risk. It is necessary to protect it, nurture it and clear its way. Never before has it been so necessary. That is why such an essay is proposed. Through the dialectical method, with a vast tradition in humanistic thinking, the following exposition aims to shape a critical inquiry - through literature review, methodological criticism and notes obtained via participatory-action research carried out throughout the Portuguese territory (2017 -2020) - on the form and meaning of the act of teaching, in the classroom, as the indivisible and most basic elemental unit of work in education at all levels, modalities and formats actually existent.

Keywords: Historical-Critical Pedagogy; Didactics; Act of Teaching.

Recebido em: 16.03.2021. Aprovado em: 31.08.2021. Revisado em: 06.09.2021. 


\section{Introdução}

Terei eu lido bem?, pergunta-se o leitor atônito. "Em pleno século XXI, e no auge das tecnologias de informação, alguém ainda teria a pachorra de realizar o elogio da aula... presencial, proximal, em directo - e 'ao vivo'!?!. O questionamento, legítimo, vem-nos bem a calhar. É que, enfim, o despojamento não conhece limites. Para além de um já algo incômodo substantivo, colmata-se com um adjetivo ora inadmissível. Magistral?: como e por quê? Já lá vamos, aos interditos do bem-pensar do ideário educacional predominante. Antes, porém, uma anedota. De há uma semana atrás e os jornais canadenses estamparam, sem temor, a gorda manchete: «Universidade usa Professor morto para dar aulas online». O invulgar dá então lugar ao insólito. Aaron Ansuini, estudante da Concordia University, em Montreal, realizou uma descoberta chocante: a de que seu professor de história da arte não estava mais vivo (!). Após assistir uma conferência digital do Prof. Dr. François-Marc Gagnon, o estudante foi buscar o seu e-mail, para colocar-lhe uma questão e, ao aceder à página institucional, descobriu o obituário: "Gagnon (1935-2019) - para um grande educador".

Por onde iniciar? A relações públicas da faculdade, de nome tão cordato e harmonioso, não poderia faltar a seu fim. A recém-contratada profissional de comunicação não hesitou. Vannina Maestracci disse, rija, que o Moodle-learning System, tal qual toda a comunicação oficial com os alunos, deixara claro, desde o início, que a lecture estava sendo ministrada por um instrutor diferente e a palestra do Prof. Gagnon era tão-somente uma, e agora cito-a ipsis verbis, "additional teaching tool". Mas Maestracci não é propriamente uma amateur. Foi porta-voz da ONU em Nova Iorque com Mestrado em Media na Columbia University. Vale a pena, aí, voltar à conceptualização de trabalho morto. Em Marx (2017) a distinção entre trabalho vivo (trabalhador) e trabalho morto (máquina) é a «forma» de toda combinação laboral ou factor típico geral do desenvolvimento da produção genericamente capitalista, e característica que abrevia o tempo necessário (à mesma). Mas é tão-só na fase ulterior, em que os empregos da nova tecnologia substituem o trabalhador vivo por alguma fatia do capital constante - i.e., aquele quinhão do produto do trabalho que se torna, novamente, meio de trabalho -, que o trabalho pretérito ressurge, como uma tendência clara e meio hábil para diminuir os trabalhadores. A essa tão fantasmática especulação empresarial o velho mouro iria chamar, no clássico Zur Kritik der Politischen Okonomie, como «meio para aumentar o mais-valor». Agora, um breve aparte sobre as palavras e as coisas: o que dá nome à aula magistral?

Do Lat. Magistr lis, referente ao exercício do magistério e realizado com maestria, é dito do tom e modais exemplares: perfeito, exacto ou afetado e professoral. O que, aliás, levar-nos-ia a Professor. Professor e Profissão são palavras que se unem etimologicamente, relacionadas por intermédio do verbo latino Proferre, o qual significa «trazer para a frente, declarar, expor etc.», isto é, aquele que apresenta assuntos. Por extensão, aula magistral poderia significar impartida em ocasião solene ou, mais simplesmente, o ato do docente. $\mathrm{O}$ fato é que magistral diz respeito a magistério, ao sentido primeiro de qualquer processo educativo: existe o sujeitoobjeto do ato de ensinar e o sujeito-objeto do ato de aprender. É um pressuposto aceitar determinada posição pedagógica para que haja ensino/aprendizagem, inserção plena em uma cultura, iniciação ativa em um modo de vida, enfim, socialização. Uma aula é, portanto, um ato magistral, e isso significa dizer que se trata de expansão, e não anulação; generosidade, e não egoísmo; ir em direção ao outro, e não a uma qualquer clausura.

Dessa maneira, por aula magistral não me refiro necessariamente a um tipo-ideal, a uma configuração, pronta e acabada. Antes pelo contrário, uma aula magistral se refere - sobretudo - ao que a move, aos valores e aos sentidos que a tornam efetiva, real, possível. O docente pode (e deve) apelar a um universo sem-fim de possibilidades em aberto, desde a exposição clássica que exercita os alunos nos tempos da escuta, vale dizer, passando pela escuta atentiva dos alunos pelo professor, até a mediação de recursos diversos que podem estimular este rapport. Pois que a aula magistral é, por fim, um autêntico reencontre. A defesa da aula magistral, portanto, só faz sentido no contexto do ensino democrático. Os alunos hoje estão por todos os lados pressionados justamente a serem passivos (redes sociais, videogames etc.). A disposição, a princípio, é essa. Chegam já à sala de aula com um rol de expectativas apassivadoras. O embate hegemónico começa aí. A aula deve ser para aprender conteúdos valiosos, uma pausa de reflexão filosófica, mas, também, o exercício político democrático, no sentido de criar um espaço propício para a interrogação sobre si, o outro, o mundo. Como fazer isso? Como realinhar a uma tal disposição? Este é o desafio de toda aula.

$\mathrm{O}$ que fazer? Faz muito que o dito «professor mediador» e as metodologias ativas, as quais não transmitem as formas sociais de conhecimento aos alunos, são uma espécie de pensamento único no que se 
refere a conceções de educação na escola ou no campus. Os docentes que, supostamente, não massacrariam a personalidade de seus aprendizes com os seus conteúdos curriculares; que, alegadamente, não seriam o centro de todo o nexo educativo (o qual deveria ser, sempre, o aluno), aqueles que, em vez da lecionação e suas respostas, deixariam reflexões e indefetíveis perguntas, seriam, por fim, catalisadores da autonomia intelectual ou da emancipação social necessárias para que então os próprios estudantes - enfim, empoderados pelo aprender a aprender - autoconstruíssem os seus próprios saberes particulares. Muito antes de qualquer pandemia, a pretensa crítica àquilo que os adversários chamam de educação tradicional adquiriu status de razão-de-Estado: flexibilidade curricular, perfil dos alunos, aprendizagens essenciais etc. etc. etc. É tal a impostação programática dos mestrados em ensino que auferem habilitação docente em Portugal.

A negativização do ato de ensino é o ponto de encontro entre teorias pedagógicas tão distintas entre si quanto o são, por exemplo, o escola-modernismo (Freinet, 1896-1966, na metodologia dos projectos), o chamado crítico-reprodutivismo (Passeron, 1930-?, na teoria dos sistemas) e o próprio pós-modernismo, que sequer reconhece o lugar da educação escolar e universitária tout court. De forma tácita e com sentidos implícitos, não é outra a visão social de mundo impressa à mal-chamada metodologia ativa, hegemônica em escolas, institutos e faculdades de todo o país. Não temos aqui o espaço necessário para desenvolver como se deve o que seria a antítese vigorosa a tais negativizações, mas cabe-nos, pelo menos, o papel de anunciá-la. Em uma conceção abertamente positiva do ato de ensinar admite-se, em primeiro lugar, que a educação como um fenómeno especificamente humano e social - é o ato volitivo e intencional de originar diretamente, para cada indivíduo singular, a humanidade que é produzida histórica e socialmente pelo género humano como um todo. O seu objeto não pode ser outro senão tanto o critério de identificação de elementos culturais que precisam ser assimilados pelos indivíduos, para que se tornem humanos, quanto, a um só e mesmo tempo, a descoberta das formas e conteúdos mais adequados para transmitir esse objetivo. (Desafio o leitor curioso a ler mais sobre a Pedagogia Histórico-Crítica e seu criador, Demerval Saviani, 2013.)

Mas por onde começar? Para sublinhar esta conceção bastar-nos-ia lembrar que, tanto a postura ereta bípede, quanto a linguagem articulada, não estão circusncritas ao DNA. Mas a ideia inicial deste artigo é outra: defender uma forma específica do ato de ensinar fundante, sobretudo, na lecionação de diversos níveis nas universidades modernas. Assim como o locus icônico - do cientista da natureza - é o seu laboratório, o habitat natural clássico do professor de humanidades é a sala de aula (seminário, anfiteatro ou auditório). É um espaço próprio, em que o professor tem o seu público alvo cativo. Assim como existem muitas maneiras de se conceber os cientistas naturais e sua relação com seus objetos de estudo, também há muitas maneiras de se pensar sobre os professores universitários e sua relação com os alunos. Uma dimensão crucial é o grau em que os professores são vistos como detentores do monopólio de conhecimento e insight, e em que medida os alunos são vistos como receptáculos vazios - tábuas rasas - por serem preenchidos, ou portadores que são de experiências vividas, significativas a serem reelaboradas reflexiva, criticamente.

As Humanidades (história, filosofia, sociologia, letras) são o cerne da Universidade. Se História, Filosofia e Literatura desvanecerem da vida acadêmica, o que restaria em seu encalço poderia vir a ser um centro de instrução técnica ou um instituto de investigação empresarial. Mas não seria nunca uma Universidade no sentido mais clássico deste termo, e seria falacioso chamá-la desta forma. Haja vista que descartá-las seria algo escandaloso (a não ser a párias da humanidade - como Donald Trump e Jair Bolsonaro - por exemplo), o que vem acontecendo nas sociedades contemporâneas é um seu relativo declínio para as classes subalternas ou o discreto (e quase clandestino) cultivo no seio das classes dirigentes. Gente séria estuda Direito e Engenharia, enquanto ideias e valores seriam para os Outros? As Humanidades devem constituir o fulcro de qualquer Universidade digna desse nome. O estudo da História e da Filosofia, acompanhado de conhecimentos em Artes e Literatura, deve ser já para Médicos e Físicos, inclusivamente para aqueles que estudam Belas Artes. A defesa da aula magistral - ou da «lecture» - só é possível em uma ambiência deste tipo.

A defesa da aula magistral não é apanágio exclusivo da Teoria Crítica da Sociedade. Jacques Rancière, Gilles Deleuze e George Steiner vaticinaram, de diferentes formas e em sentidos vários, que o locus da aula seria o derradeiro estertor de uma escuta mais atentiva. Na verdade, é mais. Quando surgiram em sua forma atual, por volta da viragem do Século XVIII, as chamadas Humanidades tiveram uma função crucial. Vieram para promover e proteger o novo tipo de valores para os quais uma ordem social filisteia tinha muito pouco tempo. As humanidades modernas e o capitalismo industrial foram - mais ou menos - géminos à nascença. Para preservar então o conjunto de valores e ideias sob sítio, seriam necessárias - entre outras coisas - 
instituições reconhecidas como universidades distantes da vida social quotidiana. Esse afastamento significava que os estudos poderiam ser, algo lamentavelmente, um tanto não utilitários. Mas também permitiu-nos que as Humanidades lançassem a crítica à sabedoria convencional e ganhassem legitimidade, dignidade própria. Um mundo ao qual a aula é algo de anacrónico é temerário para a existência social como tal.

De diferentes formas, ao longo da carreira, já ouvi a mesma narrativa em diferentes versões - até mesmo de professores. Num sindicato docente francês o personagem central era Kant, enquanto em grupos focais de professores lusófonos, em seu lugar, estava Deus. A historieta inicia com uma questão à queima-roupa: «Se Fulano ou Cicrano ressurgisse», reza o mito, «em pleno Século XXI - qual seria o único dispositivo reconhecível para si?». A resposta, em uníssono, «a sala de aula»: o quadro, o giz, as filas de carteiras, o tablado. Para uma versão empreendedora da universidade voltada para o mercado seria necessário uma novíssima arquitetónica: das tecnologias de informação aos multiespaços inteligentes. O cerco à educação escolar e à formação universitária aumentou muito no último período. Os municípios inundam escolas de Ipads; as universidades amontoam plataformas digitais. Enquanto isso, não houve programas sociais e políticas públicas de incentivo às carreiras de ensino e investigação minimamente correlatas ao investimento em maquinaria didática. Como inverter a pérfida primazia do trabalho morto sobre o trabalho vivo na educação contemporânea?

Muito provavelmente, será preciso um movimento, para além do espaço académico. Mas o movimento intra-universitário deverá, também, ter lugar. A defesa da aula magistral deve ser muito mais do que uma reivindicação corporativa. O ato de ensinar encontra-se em situação de risco. É preciso protegê-lo, acarinhálo e abrir caminho. Nunca antes foi tão necessário. A guerra declarada contra a aula magistral parte de uma caricatura: de um lado haveria um modelo sage-on-the-stage, arcaico e, de outro, o progresso técnico dos laboratórios digitais e o evolver, moderno, das forças produtivas via instrução remota online ao serviço das chamadas aulas reversas interativas ou baseadas em projectos ativos, quando muito, caso reste ainda algum papel docente, seria o do mero guide-on-the-side. A verdade é que a aula magistral persiste um portentoso instrumental de comunicação de experiências e ativação simbólica do processo de ensino-aprendizagem para o estar-juntos. Qual seria a principal objeção? Estruturas hierárquicas, não-flexíveis, unidirecionais, que não se adaptam ao novo mundo... global, dinâmico e de multitudinários recursos - ser de cima para baixo e ocorrer em horários fixos. Mas será isso tão funesto ou beneficiam-se professores e alunos?

Nas aulas não se projetam os saberes diretamente das bocas dos professores para os cérebros dos alunos - essa ideia é falsa, tosca e algo exacerbada pela frase problemática: debitar conteúdo, e já foi de-há muito criticada por Paulo Freire qual educação bancária. Embora os professores possuam informações que, no início de uma aula, são inéditas aos alunos, não se trata tanto do débito de conteúdos. Muito pelo contrário. A aula exige-nos a comunicação direta de conhecimentos especializados por meio de arguição em tempo real. A contrapêlo da noção de débito, o cimo da aula é mais uma subtração do que oferta. O desafio é mais o retirar do que colocar. Subtrair-se ao aleatório dispersivo da estrutura da vida quotidiana, do imediatismo da aparência empírica, de automatismos ideo-políticos e material-sensíveis que entorpecem, a diário, aos nossos discernimentos e sensibilidades. Sobretudo em grande recusa aos despotismos do mercado ou às tiranias do Estado central. Na sala de aula instaura-se um novo tempo-espaço distinto ao espaço-tempo convencional. É todo um convite à meditação, ao exame lento, à suspensão das adesões mais impulsivas. À filosofia.

Já o espaço da aula reconfigura mapas afetivos e coordenadas cognitivas, rearranja expectativas, mitiga exaltações, concentra a atenção dirigida, mobiliza a memória volitiva e estimula todos os processos especificamente humanos ou de nexo psico-físico superior. A aula, quando realmente ocorre, é uma autêntica arte do encontro de ordem muito antiga. Tem a ver com o sentido de pertença, partícipe da conversação altiva, do velho contar de histórias e, até, do sermão. O ensino e a aprendizagem dependem desta arte antediluviana. É o locus da aula que pode viabilizar tal encontro porque, para além de métodos e temas, ensinar e aprender só são possíveis graças à experiência comum da sociabilidade humana: das posturas, dos afetos, dos gestos e dos intelectos de pessoas inteiramente envolvidas. Trata-se de um exercício performativo - de cultura e de civilidade vivas -, o próprio gestus e a dramaticidade envolvida, uma dialéctica ininterrupta entre o distanciamento e a proximidade, de partidas ou chegadas, de começos e de fins. Mais do que programas, como letra-morta, syllabi e/ou corpora, são percursos ou travessias que estão envolvidos tanto em seu trajeto imanente e objetivo de chegar ao campus como no seu sentido subjetivo ou transcendental: são viagens, no melhor dos sentidos possíveis, autênticas jornadas que se desdobram no tempo e no espaço. 
As melhores aulas baseiam-se tanto em preparação cuidadosa e diligente quanto em revelação espontânea e surpreendente. Ao falar com os alunos, e avaliar as suas reações, tal como os velhos narradores, ao pé do fogo, os professores chegam a novas conclusões, incorporam-nas às suas aulas e refinam os seus argumentos. Em The Mirror Has Two Faces (1996) Jeff Bridges oferece monólogos impessoais sobre modelos matemáticos avançados enquanto Barbra Streisand revela-se a si mesma ao lecionar estudos literários. Quem não conhece de perto estes arquétipos educacionais? Se no primeiro caso transmitem-se tão-só factos, no segundo modelase a arguição - tal qual o mestre-oleiro e a sua criação de barro -, ao mesmo tempo em que respondem-se às sugestões não-verbais de um público interessado e interessante. Longe de ser algo opacas, unilaterais - as aulas são um denso processo social. E muito mais do que a relação educador-educando, aliás. O tempo habitual das aulas contribui para a sociabilidade e estabelece um ritmo ao curso. A aula semanal (ou o par de aulas) reúne os alunos à mesma hora e lugar, fornecendo um conjunto de ideias para se digerir enquanto lê-se material suplementar e divide-se secções de discussão menores. As salas de aula são comunidades e, normalmente, as aulas são a ocasião única para o grupo se reunir fisicamente. Removido o ímpeto de reunião - seja por conta de aulas assíncronas, gravadas, ou por se tornar toda a assistência opcional - todos os benefícios da comunidade real, de tão sólidos, desvanecer-se-ão no ar, tal como bytes, pixels ou algoritimos.

Aliás, o simples ato de se vestir, de sair de casa, de comprometer-se com um calendário e de participar de uma experiência compartilhada evita a solidão e combate ao desalento, gatilhos propulsores da exaustão e da depressão. Quando os estudantes faltam às aulas perdem oportunidades de falar com colegas ou orientadores, como mínimo, e, com algo de sorte (ou azar!) deixam de conhecer os seus melhores amigos e/ou futuros namorados. As aulas são verdadeiros reguladores do regime mesmo de controlo sócio-metabólico da comunidade académica, um ato ontológico com pontuação sobre toda a semana lectiva, o incentivo à organização dos ciclos de sono e vigília, a reordenação integral do modo de vida, a orientação de estudos/leituras, além de ajudar a prevenir consideravelmente situações potenciadoras de ansiedade/stress. Os espaços de permanência, de confraternização e/ou de convívio estudantil compartilhado refundam um tipo de decoro próprio à vida acadêmica. Isso tudo é o que fazem, uma vez decantadas nos espíritos em formação, as novas aptidões moraisintelectuais em processo. Para não dizer do mais - que vem junto com salas de aulas e o elã que suscitam.

A esfera pública fora do campus compreende claramente os benefícios do complexo categorial da fala dedicada e da escuta atentiva em colectivos. Se os cursos não atraíssem multidões notáveis ou grupos consideráveis, o que seria, ora, de museus, cafés, institutos, bibliotecas, livrarias e centros culturais à volta? (E que falta fazem bibliotecas, cafés e centros culturais!) O público sabe que - longe de serem obsoletas - as nossas aulas podem/devem ser estimulantes, profundas e até mesmo divertidas. Aliás, não há razão para se dissociar o saber e o prazer. Muito pelo contrário! É preciso reinventar - como de-há muito já preconizava Bertolt Brecht - os termos da relação entre o divertimento e o conhecimento como modos de ultrapassar uma série de distrações e entretenimentos que não nos elevam para além de nós mesmos e cuja satisfação é fugaz, intermitente ou carente de sentido. A tenaz, lenta compreensão do conceito pode ser muito mais recompensadora que o click. E não seria justo deixar de fora um facto ineludível: não existe história da universidade sem o recurso à história do movimento estudantil tal qual nos relembra, para ficar o exemplo canonico, o espectro de 1968. O associativismo político-cultural, o esporte coletivo e a vida académica fazem-nos bem.

A assim-chamada instrução remota é uma autêntica contradição em termos. Trata-se de uma fórmula que revela uma ampla lista de contradições fundamentais inexoráveis: porque não há ensino e (tanto menos) aprendizagem à distância, embora possa haver a troca ou fluxo de informações. Não aprendemos com os olhos e não vivemos na ponta dos dedos! A participação activa na complexidade de uma rede de experiências em sentido ampliado vivifica interações complexas que só a comparticipação densa e real pode vir a instaurar. Se por um lado as medidas emergenciais da legítima tentativa de redução de danos que o isolamento físico acarreta alimentam um fervor de soluções do mercado informático e ávido na pilhagem dos Big Data, além dos voluntarismos mais frenéticos de turno - algo ansiosos pelo comando do mercado e/ou pela obrigação do Estado -, por outro lado, e contrariamente às justificações jactadas, acabam por só aumentar desigualdades sociais, as opressões e uma série de injustiças sociais. Estou absolutamente convencido de que a comunidade académica poderia se valer de sua vasta tradição de autonomia e de laicidade para pensar democrática e radicalmente a superação de novos dilemas e desafios impostos à educação superior no século XXI

Os estudantes fazem um colossal investimento - afetivo, social, cultural e intelectual - quando vão às escolas, institutos e universidades. O espaço público atravessa os estudantes e é atravessado por desejos, 
necessidades, disposições vitais e orientações-para-a-ação deles. Quando um estudante entra em sala de aula pode - daí - ocupar legitimamente um lugar, participar do sistema universitário de produção de saber, ser personalizado pelo zelo e atenção do professor, fazer-se nomear pelos documentos acadêmicos, isto é, pensar e sentir como um sujeito investido de direitos e de deveres, com responsabilidades e com compromissos, de sentimentos e de pensamentos que fazem, então, toda a diferença, como o entusiasmo e a participação em seu próprio processo de formação integral. Os estudantes são sempre a mais vigorosa e lúcida figuração de futuridade que a universidade ou a escola poderão ter. É difícil conceber - em termos humano-genéricos - investimento mais extenso, profundo, na própria reconciliação da humanidade consigo mesma e o pôr-teleológico em vir a ser: a melhor aposta.

\section{Mas por que a sala de aula tem tantos inimigos/adversários no mundo contemporâneo?}

A ofensiva contra o ato de ensinar, em última instância, remete ao neoliberalismo em um sentido mais amplo, como um regime de acumulação propenso à reestruturação da vida quotidiana à imagem e semelhança da produção global flexível just-in-time: estar sempre disponíveis na luta exasperada por sermos empregáveis por qualquer entidade contratante. A aula magistral é cada vez mais questionada e interpelada como um método pedagógico- didático inactivo, hierárquico e anacrónico. O tipo de trabalho exigido em sala de aula - e o tipo de comunidade que ela aí (re) constrói -, contudo, ainda importa. Sob um modo de produção que opera sempre para nos acelerar, fragmentar e convulsionar, instituições que reservam tempo e espaço para reunir colectivo e reflexão são mais necessárias que nunca. A necessidade do isolamento físico agravou problemas estruturais à dinâmica académica. A suspensão das atividades lectivas, e do ritmo emergencial acadêmico, poderia ser uma bela ocasião para repensar os reptos que a educação contemporânea em crise enfrenta e quais os horizontes poderiam ser priorizados no sentido da missão que anima à sua crítica. É preciso reinventar-se à lecionação como verdadeiro projeto político-pedagógico de transformação.

Em resposta a tão dura ofensiva, contra a forma didática das aulas magistrais, e sob o assédio do elearning online ou tutoriais minimalistas, este ensaio tenta oferecer-nos não apenas uma defesa, mas também afirmar que o potencial valor histórico-universal da aula magna é difícil de replicar por meio de outros formatos de aprendizagem. Algumas das críticas devem ser desafiadas abertamente, em especial as de que seria monológica ou promoveria certo conceito bancário, de débito de informação (e não produção de saber). Para isso, deveremos desenvolver, fortemente, o conceito de linguagem interna, o qual não deixa de ser a base sine qua non sobre a qual se erige o pensamento abstracto, i.e., duas funções psíquicas superiores apoiadas sobre o sistema de signos, especificamente humanas e centrais para todos os homo sapiens sapiens - devemos reafirmar a virtude da fala dedicada sob uma escuta atentiva. O tipo de pensamento apropriado para o ensino superior pode e deve ser incentivado pelo docente enquanto um condutor que pensa em voz alta - os hábitos intelectuais fulcrais para as humanidades, e a universidade, não são de gestão inata ou geração espontânea: aprendem-se. Não há nada de mais radicalmente democrático que o ato de ensino.

Então, quando os ouvintes estão interpretando e adjudicando sentido aos sons da fala emanados pelo docente, eles não estão apenas decodificando a estrutura gramatical da língua falada - para desvendar o seu significado -, acorde ao esquema de um niilista da linguagem sobre a atividade em estudo: um sistema linear, fechado, que envolveria tão-só recebimento, decodificação e armazenamento (ora ignorando, ora rejeitando), na verdade trata-se de um constante e ininterrupto arranjo e rearranjo, em referência a seu próprio paradigma de entendimentos conceptuais, como uma conversa ou diálogo interno consigo mesmo. O dialogismo desta concepção implica, sempre, o processo de uma relação social. E a escuta atentiva é muito mais que a mera recepção passiva de conteúdos por outrem! Os bons ouvintes auscultam propaganda eleitoral com senso crítico, ouvem o primeiro-ministro com escuta atentiva e entendem um ao outro - aptidão estimulada por esta forma. Se pararmos para pensar, não existe nada de edificante, fundamental ou digno de nota na vida social que não provenha desta aptitude primordial desenvolvida ao largo da história pela cultura humana.

Parte dessa atividade interna refere-se ao predomínio do esquema de compreensão activa sobre e (até) acima das palavras reais que estão sendo recebidas e/ou quaisquer significados assumidos como inerentes: a predominância do sentido sobre o significado, da frase sobre uma palavra e do contexto geral sobre tal frase. Há uma tendência à predicação como forma basilar de sintaxe da fala interna. Ao invés de ouvir passivamente, e 
aceitar um discurso, há uma atividade contínua acontecendo dentro das pessoas, onde a relação do pensamento com a palavra não é uma coisa, mas um processo, um movimento contínuo de ida e volta, de passo do pensamento à palavra e da palavra ao pensamento. Trata-se de um engajamento dialéctico - denso e real - e não um esquema positivista, tipo estímulo-e-resposta. A relação entre pensamento e linguagem, para o nexo educativo realmente existente, é o divisor de águas predominante entre um ensino voltado para a formação humana e uma instrução mediada pela forma-mercadoria, e os respetivos «descritores de competência», algoritimizados estes por artefatos de inteligência artificial. Este é seu segredo de polichinelo.

O modo de vida neoliberal também dificultou o reconhecimento da atividade que os alunos realizam nas aulas. Muitos críticos menosprezam a freqüência às aulas enquanto aprendizado passivo, argumentando que os alunos nas aulas não estariam fazendo nada. Hoje, declarar algo como passivo deslegitima-o completamente. O que é relevante é estar sempre em busca de algum tipo de activismo: nunca estar sem um projecto. Na verdade, nesta inglória batalha para projectar o modelo da empregabilidade adaptável, todos devem estar perturbados, e mesmo que toda esta agitação não seja direcionada a nada em especial. Sem se mover ou até falar, os participantes das aulas, certamente, não parecem ocupados e, enfim, a sua actividade peremptoriamente é considerada inactiva, improdutiva: conseqüentemente; algo irrelevante. Mas os participantes das aulas fazem muitas coisas: tomam notas, reagem, vasculham a sala em busca de reações e, o mais importante!, ouvem. Ouvir uma discussão longa de uma hora requer controle da própria conduta, atenção dirigida e muito foco. Em outras palavras, toda uma atividade. $\mathrm{O}$ ato de ouvir hoje conta bem pouco - o que não deixa de ser um sinal dos tempos: hoje estamos (muito) mais pobres sobretudo de experiência vivida.

Embora, possivelmente, não tenham pensado nesses termos, muitos dos críticos da aula magistral, provavelmente, favoreceriam certos tipos de conhecimento que alienam o trabalho da teoria do trabalho da prática. A teoria (episteme, scientia) descreveria um conhecimento baseado na investigação categorial (filosófica) e/ou na demonstração empírica (histórica). Já a prática (praxis, experientia) englobaria as coisas feitas - política, economia etc. - ou coisas por fazer, techn, que exigem trabalho físico. Antes da era moderna, a techn era amplamente denegrida. Já, segundo Adam Smith (1776), a techn era o conhecimento inferior de como se fazer coisas ou produzir efeitos, praticado este por animais, escravos e artesãos - isto é - a única área propriamente produtiva do conhecimento. Hoje, claro, a situação mudou - e muito. A qualidade produtiva da techn eleva-a já acima da teoria, supostamente, impraticável. Qualquer coisa que não pareça já imediatamente produtiva é descartada como tremenda perda de tempo ("time is money"). Por isso o mundo tornou-se simultaneamente tão hostil ao saber e à beleza. Sim, pois para além de Teoria, Práxis, Techn - a hegemonia neoliberal privounos também de toda Poiésis.

Sessões de discussão colectiva, após as aulas, sempre revelam ouvintes experientes. Eles fazem as melhores perguntas - aquelas que vão direto aos temas principais das aulas, com uma emergência e acutilância que eletriza a todo o público, produzindo uma enxurrada de respostas empolgadas, perguntas complementares ou debates paralelos. A boa escuta fundamenta um diálogo, expande o corpus de saber - e constrói às comunidades. O ato de ensinar é a «alma» de tudo aquilo que conforma o trabalho-real-na-educação. E está em franco perigo. A educação, a leitura, a reflexão desinteressada e a tarefa crítica são o espírito dum mundo cada vez mais carente de alento íntimo, força anímica e base de amparo - para além do gélido cálculo egoísta e da dominação do homem sobre o homem. A defesa da aula magistral, portanto, vai muito além de um discurso especializado e/ou de algum grupo de interesse. A defesa de certa remissão a valores é - de facto e de iuris - a reedição de uma encarniçada batalha que, como já vimos, deu lugar às Humanidades e à própria Universidade. Lembrar é resistir: para além das Humanidades ou da Universidade, é todo um programa de defesa da Universalidade da própria Humanidade - em si e para si. Nos novos tempos neoliberais, de tirania do mercado e de despotismo do Estado, a defesa do ato de ensinar - desde a educação pública global - é a viva defesa do interesse da humanidade como um todo.

Aquilo que o Prof. Dr. Denilson Soares Cordeiro nomeou (corajosamente) enquanto "o ato docente na era da sua reprodutibilidade técnica" - em uma vigorosa e nova síntese, entre o ensaísmo de dois ilustres mestres à contramão da educação-mercadoria, tais como Antonio Cândido e Walter Benjamin (1993) - é uma importante contribuição para se tratar das preocupações com o momento atual, em que os efeitos da trágica (e ineficaz) maneira de enfrentar a pandemia vem tensionando toda uma significativa reconversão do saberfazer docente, que abre caminho para o aprofundamento da precarização, novas desigualdades educativas, rebaixamento qualitativo e muitas outras consequências, as quais nem sempre comparecem ao debate público 
em razão duma espécie de adesão acrítica ao processo de ensino-aprendizagem mediado pelas tecnologias da informação. Mas não se trata só disso. Este ato docente na era da reprodutibilidade técnica não surgiu como um raio em céu azul. Com luvas de pelica ou soqueira inglesa, de há muito que se prenunciava o seu vir a ser: golpe a golpe, verso a verso.

A defesa mais intransigente do ato de ensinar, ademais, não deve abrir um flanco à ofensiva em curso, desde as teorias da formação de um suposto professor reflexivo, cuja razão de ser primordial seria uma das variantes mais desenvolvidas das ditas pedagogias do aprender a aprender. Os seus slogans e modismos educacionais - a orbitar ao redor da ideia-força de Donald Schön (1997), em "reflective practioner" - seriam de que o professor não deveria ser "um simples transmissor de conteúdos", mas, isto sim, «adaptar» as suposições empregadas em aula à realidade imediata e à necessidade situacional dos educandos reais. Mas a socialização orientada das formas sociais de conhecimento produzidas ao largo da história humana não pode nunca ser subsumida ao elogio fetichizado da quotidianidade. O esvaziamento do conteúdo (e currículo) dos processos de ensino-aprendizagem reivindica-se hoje desde a revalorização maximizadora de um suposto «lugar de fala» estranhado em base ao senso comum - daí a proposição da inovação didáctica, norteada pela reificação ideal das tecnologias de informação, cobra então o preço real de amoldamento das consciências sociais aos desígnios do mercado - e a subtração do ato de ensino sistemático e orientado das formas culturais historicamente ordenadas e complexas do saber objetivo enquanto tal.

Mas atenção. Antes de qualquer conclusão perentória é preciso pôr os pingos nos is. Ninguém aqui defendeu uma exclusividade da forma didática que dá azo à aula magistral. $\mathrm{O}$ ato docente pode e deve ser plural, aberto e dinâmico - numa multitude de formas e de sentidos. As aulas magistrais podem e devem ser sucedidas por seminários de autogestão discente, leituras coletivas, debates a partir de filmes, canções, poesias e romances. E tanto mais, como é evidente. Como já o dissemos, o ato docente não só é ato responsável como é ato responsivo, dialógico e, portanto, social: pressupõe o encontro e reconciliação com a nossa própria humanidade. Formar este tipo de professor, contudo, leva tempo e demanda investimentos maciços nas carreiras docentes, na qualificação profissional e na seguridade laboral. Caso não os queiramos meros leitores de PowerPoint e monocórdicos palestrantes também o educador deve ser educado. E nenhuma autêntica reforma intelectual e moral no ensino poderá advir sem uma verdadeira revolução democrática no âmago de toda a sociedade.

Enfim, a respeito do espírito do tempo de nossa própria época, vale a pena que nos detenhamos precisamente sobre o que não deixa de ser algo como um "tempo do espírito." Como já disse no início, aqui e agora estamos a tratar sobre aquilo a que chamamos, de uma forma até hoje reconhecida, como Humanidades (História, Filosofia, Literatura etc.), em geral e, no particular, uma de suas formas mais representativas, isto é, a aula magistral. Não à-tôa os alemães designaram o ramo de estudos relacionado a disciplinas tais como as de Filologia, Linguística e Estética, p. ex., como «Geisteswissenschaft», em uma tradução algo ligeira, Ciências da Alma. O conceito de «Geist» remonta à história do idealismo alemão, dos Séculos XVIII e XIX, e em particular a Georg Hegel e seu espírito universal, ou a sua personificação, em algum espírito do povo (de qualquer modo, transindividual). O historiador Wilhelm Dilthey foi quem popularizou a distinção mais fundamental entre «Naturwissenschaften» (ciências naturais) de um lado, e as Geisteswissenschaften, de outro.

O tempo da leitura concentrada não é o mesmo do bombardeamento ininterrupto de estímulos a respostas. O tempo da escuta atentiva não é idêntico à recepção de mensagens instantâneas. A hiperconexão virtual não deixa de constituir uma brutal desconexão de tipo específico, posto que os liames que suportam aquilo que classicamente pensamos edificar a integridade da pessoalidade humana em um sentido integral são amortecidos e entorpecidos. A verdade é que o tempo médio de trabalho vivo e socialmente necessário da maioria da população trabalhadora é hoje mais intenso, acelerado, flexível e muito mais longo do que em qualquer momento da história moderna e contemporânea da humanidade. E não apenas na indústria ou na agricultura mas, quiçá em cheio, no trabalho intelectual e de serviços em geral. Tanto é assim que o próprio ciclo de sono e vigília foi absolutamente perturbado pelo capitalismo realmente existente. As sociedades competitivas e orientadas ao mercado estão cobrando um preço - cada vez mais - insuportável às individualidades modernas tardias.

Em vez de melhorar a vida - o multitasking, as tecnologias amigáveis e a cultura da conveniência - estão produzindo transtornos que vão da depressão à Síndrome do Burnout e ao próprio transtorno da personalidade limítrofe. O stress laboral e a exaustão emocional não são apenas experiências episódicas com os factores de adoecimento individual, mas sobretudo fenômenos histórico-sociais mais amplos, ou seja, são questões públicas gerais. Os graves riscos de se sacrificar a reflexão intelectual intermitente por uma conexão neural 
constante já começam a cobrar a fatura. Também e principalmente neste sentido devemos defender de forma intransigente um tempo do espírito apesar e contra os tempos do capital. O elogio da aula - ou a defesa da aula magistral - não deixa de ser então uma proposição ou alegação em direção a um tempo próprio do Espectro da Humanidade, o ente-espécie, ou as Humanidades, como ramo do conhecimento. Afinal, como já se disse uma vez, nada de humano nos é alheio.

P.S.: Não existe lecture sem lecturer - e não, não pode haver qualquer aula sem o trabalho vivo de um docente.

\section{Referências}

BENJAMIN, W. A obra de arte na era da sua reprodutibilidade técnica. In: BENJAMIN, W. Magia e técnica, arte e política. Obras escolhidas 1. São Paulo: Ed. Brasiliense, 1993.

BRECHT, B. O rádio como aparato de comunicação. Estudos Avançados, São Paulo, v. 21, n 60, p. 227-232, ago. 2007.

CORDEIRO, D. A formação do discernimento. Tese (Doutorado em Filosofia) - Faculdade de Filosofia, Letras e Ciências Humanas, Universidade Federal de São Paulo, 2008.

CORDEIRO, D. O Ato Docente na Era da sua Reprodutibilidade Técnica. Revista de Filosofia Moderna e Contemporânea, Brasília, v.8, n.3, dez. 2020, p. 207-224.

MARX, K. Zur Kritik der Politischen Okonomie. Berlin: Hofenberg, 1 maio 2017.

SAVIANI, D. Pedagogia Histórico-Crítica. São Paulo: Autores Associados, 2013.

SCHÖN, D. Formar professores como profissionais reflexivos. In: NÓVOA, A. (Org.). Os professores e a sua formação. 3. ed. Lisboa: Dom Quixote, 1997. p. 79-91.

THE MIRROR Has Two Faces. Diretor: Barbra Streisand. Califórnia: TriStar Pictures, 15 nov. 1996.

\section{Roberto della Santa}

rdellasanta@fcsh.unl.pt

Doutor em Ciências Sociais pela Faculdade de Filosofia e Ciências da Universidade Estadual Paulista (UNESP/ Marília)

Investigador Integrado do Instituto de História Contemporânea da Faculdade de Ciências Sociais e Humanas na Universidade Nova de Lisboa, Portugal

Professor Convidado do Programa de Pós-Graduação de Serviço Social e Desenvolvimento Regional da Universidade Federal Fluminense, RJ, Brasil

Co-Coordenador Científico do Observatório para as Condições de Trabalho e Vida, Projecto

Nova4TheGlobe, Lisboa, Paris e Rio de Janeiro (Portugal, França e Brasil)

\section{UNL}

Universidade Nova de Lisboa.

Rua Campus de Campolide Lisboa 1099-032 Lisboa, Grande Lisboa, Portugal.

\section{Agradecimentos}

Agradeço o trabalho coletivo de todos os colegas do Observatório para as Condições de Vida e Trabalho — sem ele tudo o que deste material é feito seria impensável e, no limite, impossível.

Agência financiadora

Não se aplica.

Contribuições das autoras

Não se aplica.
Aprovação por Comitê de Ética e consentimento para

participação

Não se aplica.

Consentimento para publicação

Consentimento do autor.

Conflito de interesses

Não há conflito de interesses. 